\title{
The impact of motivation and teachers' autonomy support on children's executive functions
}

\author{
Zrinka Sosic-Vasic ${ }^{1}$, Oliver Keis ${ }^{2}$, Maren Lau ${ }^{2}$, Manfred Spitzer ${ }^{1,2}$ and Judith Streb ${ }^{3}$ \\ 1 Department for Psychiatry and Psychotherapy, University Clinic of Ulm, Ulm, Germany \\ ${ }^{2}$ Transfercenter of Neuroscience and Learning, University of UIm, UIm, Germany \\ ${ }^{3}$ Department of Forensic Psychiatry and Psychotherapy, University of UIm, UIm, Germany
}

\section{Edited by:}

Yusuke Moriguchi, Joetsu University

of Education, Japan

\section{Reviewed by:}

Kei Mizuno, RIKEN, Japan

Helen St. Clair-Thompson, University

of Newcastle, UK

\section{${ }^{*}$ Correspondence:}

Zrinka Sosic-Vasic, Department for

Psychiatry and Psychotherapy,

University Clinic of UIm,

Leimgrubenweg 12-14, 89075 Ulm,

Germany

e-mail:zrinka.sosic@uni-ulm.de
The present study investigates the interplay of executive functions, motivation, and teacher's autonomy support in school context. In a cross-sectional study design 208 students from different school types completed a standardized motivation questionnaire and processed two executive function tasks. All teachers who teach these students were asked about their autonomy supporting behavior by a standardized test. Multilevel analyses assessed the effects of the student's motivation and their teachers' autonomy support on student's executive functions. Our results show considerable relationships between these variables: high executive function capacities came along with teacher's autonomy support and student's intrinsic motivation styles, whereas low executive function capacities were related to external regulation styles. The results indicate the importance of autonomy support in school instruction and disclose the need to popularize the self-regulation approach.

\section{INTRODUCTION}

Cognitive abilities influence the way children succeed in school. For example, low levels of cognitive abilities at school entry are associated with lower later academic achievement, greater retention and special education referral, and furthermore have the potential to enhance dropout rates in school (Carnegie Council on Adolescent Development, 1995). Among different cognitive abilities, the so-called intelligent quotient (IQ) is one of the most empirically investigated factor influencing learning. However, in recent years there has been a growing body of evidence indicating that other cognitive factors such as executive functions may play a role in learning during childhood and adolescence (Swanson, 1993; Lehto, 1995; Lorsbach etal., 1996; Russell etal., 1996; Swanson et al., 1996; Bull et al., 1999; McLean and Hitch, 1999; Ozonoff and Jensen, 1999; Duckworth and Seligman, 2005; St Clair-Thompson and Gathercole, 2006). Executive functions can be understood as a set of separate cognitive components interplaying and operating together in response to cognitive and behavioral demands requiring self-regulation. Converging research suggests that executive functions may be best conceptualized as consisting of three separable, yet related dimensions: working memory (Miyake et al., 2000; Huizinga et al., 2006), inhibition (Welsh et al., 1991; Pennington and Ozonoff, 1996; Brocki and Bohlin, 2004), and cognitive flexibility (Miyake et al., 2000; Huizinga et al., 2006; van der Sluis et al., 2007). However, many researchers have used the term shifting instead of (cognitive) flexibility (e.g., Miyake et al., 2000) and have differentiated two kinds of shifting, namely attention shifting and response shifting. Together, these three cognitive processes build a fundamental basis for selfregulation and therefore may represent important predictors for academic achievement. For example, if a child has impairments in working memory, it may have trouble remembering and following teacher directions or memorizing and recalling task-related information when needed. Or, if a child has impairments in inhibition, it may have trouble focusing on given tasks without being constantly distracted by other (sometimes more appealing) impulses, or, such as child may fail to inhibit socially non-desirable behaviors in its learning environment such as kindergarten and school classroom. Yet, another example, if a child has impairments in cognitive flexibility/shifting, it may get stuck on a thought, perseverating only on that topic, even though other impulses are given that might lead to the appropriate direction.

Cumulating research data supports the idea of executive functions serving as a key predictor of academic achievement. Most studies have focused on executive functions in preschoolers, showing that those preschoolers with strong executive functions achieve higher levels of literacy, vocabulary, and mathematics compared with children with lower executive functions (Espy et al., 2004; Blair and Razza, 2007; McClelland et al., 2007). Other research suggests that executive functions skills may enhance the school readiness of children in general, as well as from disadvantaged homes (for review see Blair, 2002; Fuhs and Day, 2011). Even though comparable sparse, some research has examined the relation between aspects of executive functions and school achievement. For example, cognitive flexibility is associated with non-verbal reasoning and reading in 9- to 12-years old school children (van der Sluis et al., 2007), while working memory was found to be uniquely associated with reading comprehension in 9- to 15years old school children (Sesma et al., 2009). Other groups again have tied working memory to reading and math skills in elementary students (Kail, 2003). Furthermore, previous findings have reported associations between working memory skills and national curriculum assessments of English, mathematics, and science in English school children (Gathercole and Pickering, 2000a,b; 
Gathercole et al., 2003, 2004; Jarvis and Gathercole, 2003; St ClairThompson and Gathercole, 2006). Over all, working memory skills are found to play a substantial role for all or some of the skills assessed by English tests: reading (e.g., Swanson et al., 2004) and writing (see Swanson and Berninger, 1994, 1995 for a review). The development of executive functions in children and adolescents is reasonably well understood (e.g., Carlson, 2005). Several studies indicate an age-related gain in executive functions such as working memory (Casey et al., 2000; Vuontela et al., 2003), inhibition (van der Molen, 2000), cognitive flexibility like task switching (Cepeda et al., 2001), adaptive problem-solving (Chelune and Baer, 1986), and several other planning and problem-solving tasks (Welsh et al., 1991).

However, little is known about the sources of individual differences in executive functions. Within a biological framework, a common hypothesis is that the development of executive functions is the result of the maturational unfolding of the genetic program (e.g., Diamond, 2002; Garon et al., 2008) and that individual differences in executive functions are largely genetically determined (Friedman et al., 2008). By contrast, according to a social relational approach (Carpendale and Lewis, 2006; Lewis and Carpendale, 2009), the development of executive functions involves social and biological factors, and social interaction plays an important role in explaining individual differences in executive functions (e.g., Carlson, 2009). Several studies exist that explore whether and how social factors influence individual differences in executive functions. Among these, parenting scaffolding has been examined. According to Wood et al. (1976) and Bernier et al. (2010) scaffolding can be understood in terms of parental support of a child's autonomous problem solving, whether verbally or physically mediated. Indeed, a handful longitudinal studies showed substantial relations between parental scaffolding in early childhood and later executive functions (Landry et al., 2002; Hughes and Ensor, 2009; Bernier et al., 2010; Hammond et al., 2012).

In sum, higher levels of executive functions have been associated with academic achievement. Furthermore, pioneer work suggests a social component being responsible for the development of individual differences in executive functions.

\section{MOTIVATION STYLES IN CHILDREN AND ACADEMIC ACHIEVEMENT}

Despite the widely acknowledged contribution of cognitive abilities to academic achievement, research data indicate consistently that cognitive abilities alone fail to have enough power predicting educational success. Many factors seem to influence how children and adolescents in school succeed. Among these, motivation is considered to play a crucial role. One widely accepted and well investigated theoretical and empirical approach to motivation is self-determination theory (SDT; Deci and Ryan, 1985; Ryan and Deci, 2000). SDT proposes different types of motivation reflecting different levels of autonomous self-regulation. On a continuum from the lowest to the highest levels of selfregulation, there are external regulation, introjected regulation, identified regulation, and intrinsic motivation. Intrinsic motivation refers to the incentive to perform an activity for its own sake, for the inherent interest in that activity (Ryan and Deci, 2000), while extrinsic motivation refers to the incentive to perform an activity for instrumental reasons that are separate from the activity (Deci et al., 1991). High levels of autonomous self-regulated motivation such as intrinsic motivation are fostered by the experience of three fundamental basic psychological needs, that is, the needs for autonomy (i.e., experiencing a sense of volitional and psychological freedom), the need for competence (i.e., experiencing personal effectiveness), and the need for social relatedness (i.e., experiencing closeness and mutuality in interpersonal relationships). In contrast, little experience of these needs will results in decreased motivation and decreased overall well-being with the result of little self-determined behavior. This view is based on strong empirical support indicating how self-determined behavior is associated with diverse positive consequences in various life domains (Vallerand, 1997; Deci and Ryan, 2000). The strongest support for SDT stems from investigations in the educational domain showing several positive outcomes of self-regulated motivation styles to learning, such as higher feelings of self-perceived and teacher-perceived academic competence (Fortier et al., 1995), the use of optimal learning strategies (Yamauchi et al., 1999), the use of less defensive coping styles (Ryan and Connell, 1989), greater motivation to attend and participate in class or higher school grades (Reeve et al., 1999; Black and Deci, 2000; Vansteenkiste et al., 2004; Guay et al., 2008). In sum, highly autonomous self-regulatory motivation styles depend strongly on the experience of autonomy, competence, and social relatedness.

\section{TEACHERS' SELF-REGULATORY SUPPORT AND ACADEMIC ACHIEVEMENT}

However, in contrast to stable personality traits, expressions of motivation show great inter-individual differences. Social or environmental factors such as teacher behavior can influence how students motivationally respond and act in school. According to the SDT model of the teacher-student relationship, motivation styles strongly depend on high autonomy supportive versus high controlling environments. Autonomy support refers to teachers' promotion of volitional functioning and teachers' fostering of a sense of initiative and interest in students. Autonomy support is contrasted with a controlling interpersonal style, that is, a style where teachers ignore the students' perspective and pressure the students to think, act, or feel in a particular way (Deci and Ryan, 1994; Reeve, 2009; Grolnick, 2013). Respectively, students who perceive their teachers as autonomy supportive are more likely to experience higher levels of intrinsic motivation due to a satisfaction of basic needs. Empirical research has consistently shown that an autonomy-supportive teaching style is positively associated with more school engagement (Assor et al., 2002), higher grades and better school adjustment (Ryan et al., 1994; Fortier et al., 1995; Guay and Vallerand, 1997; Wentzel, 2002; Patrick et al., 2012), higher classroom engagement (Reeve et al., 2002; Tsai et al., 2008), more positive emotionality (Reeve and Jang, 2006), creativity (Amabile, 1985), and persistence in school (Vallerand et al., 1997).

In contrast, teachers' support is negatively associated with students experience stress (Torsheim and Wold, 2001; Assor et al., 2005). But moreover: research has provided evidence for a positive relationship between teachers' autonomy support and 
higher levels of self-determined learning (Grolnick et al., 1991; Reeve et al., 1999). In contrast, controlling environments, such as engagement-contingent reward (Deci, 1971) or deadline and surveillance (Deci etal., 1999) are associated with a feeling of coercion that diminishes motivation. In sum, environments that support autonomous self-regulated learning such as autonomous supportive teachers influence students' motivation orientation and degree of self-regulated learning strategies.

In order to add to the existing literature, we investigated the interplay between executive functions in school children and psychological and social factors such as motivation styles and teachers' autonomy support, respectively. From the standpoint of research on learning and developmental psychology, there is a growing need to increase our understanding what affects interindividual differences in the development of executive functions as a core requirement for motivation. To our knowledge, to date only one study examined the interplay of executive functions and motivation in school children. Mizuno et al. (2011) found that decrease in capacity for verbal working memory was associated with the prevalence of decrease in intrinsic academic motivation among junior high school students. According to Mizuno et al. (2011) intrinsic academic motivation must engage the working memory system to relate achievements to an ultimate goal. Especially while learning at school, the working memory maintains a limited amount of currently relevant information so that it is available for immediate use. Thus, function of working memory (which is included in executive function) permits goal-directed behavior.

In the present study, we implemented a cross-sectional study design within a sample of primary and junior high school children and administered different executive function tests and self-report scales measuring motivation styles and autonomous self-regulation support by teachers. We expect motivation styles in children and teachers' autonomy support to act as modulators of inter-individual differences in the development of executive functions, i.e., individual expressions of intrinsic motivation styles would be associated with higher levels of executive functions, and vice versa, while individual expressions of highly controlling behavior would be associated with lower levels of executive functions in children and adolescents, and vice versa.

\section{MATERIALS AND METHODS PARTICIPANTS}

In a cross-sectional study we tested and questioned 208 children and consulted 150 teachers. We only consulted those teachers that were regularly in contact with the tested children either as class teacher or as specialist subject teacher. 208 children of different ages and from different schools participated: we investigated 50 primary school children (grades: 3 and 4, mean age: 9.18, SD: 0.774 , range: $8-11$ years, 23 boys/27 girls), 83 junior high school children attending so called middle schools (grades: 5 and 6, mean age: 11.29 , SD: 0.877 , range: $10-14$ years, 44 boys/39 girls), and 75 junior high school children attending so called Gymnasien (grades: 5 and 6, mean age: 11.07 , SD: 0.800 , range: $10-13$ years, 36 boys/39 girls). In Saxony, two types of junior high schools exist: middle schools and Gymnasien. After running through primary school most of all children were allocated to Gymnasien (63\%; see PISAKonsortium Deutschland, 2008). One third, the cognitively less powerful children, transfer to middle schools. All children volunteered for participation after an informative meeting. Children and parental informed consent to participate were obtained in writing prior to data collection. In addition, 58 primary school teachers (mean age: $47.69, \mathrm{SD}: 9.349$, range: $23-63$ years, 50 female/ 8 male), 49 junior high school teachers of middle schools (mean age: 47.88 , SD: 7.336, range: $27-61$ years, 42 female/7 male), and 43 junior high school teachers of Gymnasien (mean age: 46.05, SD: 9.127, range: $26-58$ years, 35 female/ 8 male) were surveyed. The teachers volunteered for participation after an informative meeting and signed an informed consent. The study was approved by the local internal review board of the Medical Faculty of the University of Ulm.

\section{PROCEDURE}

Children attended regular school and were tested at times were regular school lessons were usually held, so they did not have to appear at additional time. In order to carry out tests on executive function children had to move to a computer room and were tested in small groups. Children and teachers questionnaires were distributed at school. Children got a short instruction by a member of the project team and completed the form in the classroom. Teachers had the opportunity to answer their questionnaire at home and handed it back after a few days.

\section{MATERIAL \\ Executive function tests}

To assess executive functions in children we implemented the dots task (Davidson et al., 2006) and the Eriksen flanker task (Eriksen and Eriksen, 1974) as computer based tests (see Figure 1). Both tasks are appropriate for ages 4 through adults.

In all conditions of the dots task a red heart or blue flower appeared on the right or left of a fixation cross. Children run through three conditions: in the congruent condition solely red hearts were presented and the children were told to press the mouse button on the same side as the stimulus. In the incongruent condition solely blue flowers were presented. Now the children were told to press the mouse button on the opposite side as the stimulus. This condition requires that children inhibit the tendency to respond on the same side (the so-called Simon effect, Lu and Proctor, 1995). In the third condition, the mixed condition, congruent and incongruent trials were intermixed in equal shares. The mixed condition was the most challenging, since it required that children remembered two rules ("press on the same side as the red heart" and "press on the side opposite the blue flower") and inhibit the tendency to respond on the same side as the stimulus on onehalf of the trials. First, children handled at least 20 congruent, 20 incongruent, and 20 mixed practice trials. In order to control for floor-effect, the test started as soon as a child passed the mixed practice trials with less than five errors. During the test children performed a block of 40 trials in the congruent condition, a block of 40 incongruent trials and 40 mixed trials. The inter stimulus interval was $500 \mathrm{~ms}$, stimuli were presented for $750 \mathrm{~ms}$. Feedback was provided during the practice but never during performance of the test. 


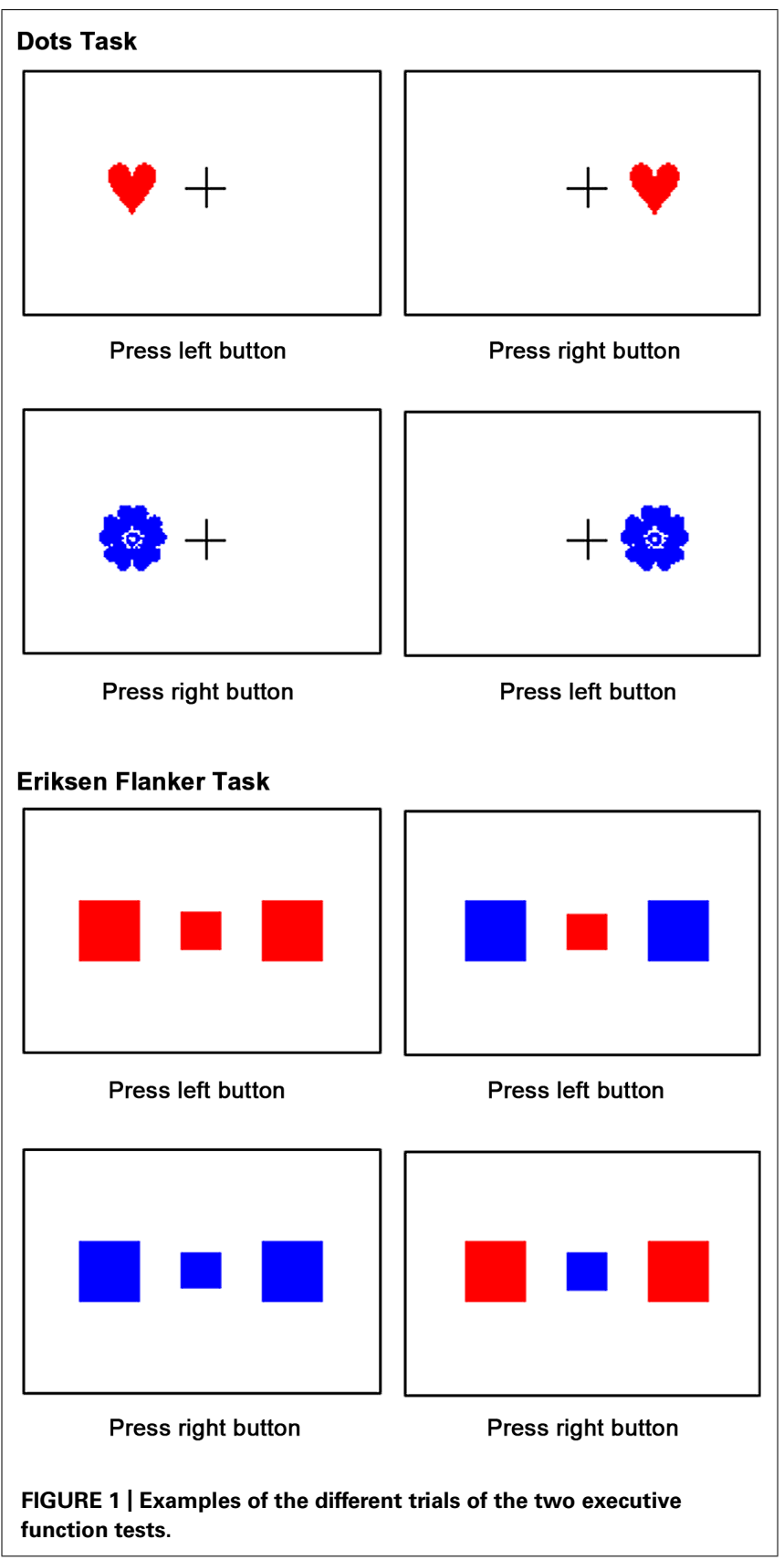

During the Eriksen flanker task children focused on the color of a small red or blue rectangle (i.e., the target) presented in the center of the screen. The target stimulus was flanked by two rectangles that appeared $4.5 \mathrm{~cm}$ to the left and to the right of the target that were either red or blue. Height and width of each flanker was three times that of the target. Target and flanker were displayed simultaneously. In the congruent condition both, target and flanker, matched in color. In the incongruent condition the flanker were blue when the target was red and vice versa. Children were instructed to respond depending on the color of the target by pressing the left or right mouse button with their dominant hand. Stimuli were presented until button press, the inter stimulus interval was $500 \mathrm{~ms}$. Appearance of the four combinations of target and flanker color was equiprobable (blue-blue, blue-red, redblue, red-red). Prior to the test, children completed 60 practice trials (half congruent, half incongruent) and the final test comprised 40 congruent and 40 incongruent trials, with randomized order of trials.

All executive function tests were conducted via computer presentation positioned at eye level and at a distance of $50 \mathrm{~cm}$ from the children. The mouse was placed on a table in front of the children at a comfortable distance. The response keys were the left and right mouse key marked with different stickers. In general, children were instructed to respond as quickly and accurately as possible.

Both tasks assess all three major executive function domains inhibition, working memory, and cognitive flexibility (see Diamond et al., 2007a,b; Diamond, 2013). The Dots task requires that subjects remember two rules in working memory (for hearts press on the same side as the stimulus; for flowers press on the side opposite the stimulus). In the congruent condition, one rule applies ("press the button on the same side as the heart"). The incongruent condition also requires remembering a rule ("press the button on the side opposite the flower") but in addition it requires inhibiting the tendency to respond on the side where a stimulus appears. In the mixed condition two abstract rules have to be held in mind (=working memory), cognitive flexibility is needed to switch between rules, and inhibition is needed on incongruent and switch trials. Both the congruent and incongruent Flanker conditions require inhibition and some memory of the rules (though memory aids are provided). The incongruent condition also requires inhibition of what they have just practiced and thus the cognitive flexibility to change the focus of attention and stimulus-response mappings.

The output of the executive function tests was prepared as follows: response times faster than $200 \mathrm{~ms}$ were considered too fast to be in response to the stimulus and excluded from further analyses of error rate (accuracy) and reaction time (speed). The error rate was calculated by dividing the number of incorrect responses by the sum of correct plus incorrect responses. The reaction time was calculated for correct responses only. The dependent measures mean reaction times and mean error rate were computed separately for each participant and each condition.

\section{Children questionnaire}

The academic self-regulation questionnaire (SRQ-A) by Connell and Ryan (1986) concerns the reasons why children do their school work. The questionnaire asks why the respondent does a behavior (or class of behaviors) and then provides several possible reasons that have been preselected to represent four different styles of motivation, namely intrinsic motivation, identified regulation, introjected regulation, and external regulation. Intrinsic motivation is the most self-determined motivation style. Intrinsic motivated children pursue an activity out of interest and enjoyment and without external contingencies. Identified regulated children undertake an activity because they accept the value of the activity. Introjected and external regulation styles are the less self-determined forms: introjected 
regulated children partake in an activity because of internal pressures such as guilt or shame. External regulated children pursue an activity because of external pressures or incentives. Respondents rate the degree of appropriateness of each of the provided reasons on a four-point scale. We computed mean scale values for each participant and each subscale were computed. To keep the complexity of our design within reasonable limits, we focus on the extreme scales intrinsic motivation and external regulation.

The scale was developed for students in late primary and secondary school and translated in German using the systematic back-translation technique. Analyses of psychometric properties of the original version revealed moderate to high levels of internal consistency for the four subscales ranging from 0.62 to 0.82 (Connell and Ryan, 1986). A series of pre-tests evaluating our German translation were conducted with a total of 59 children from primary and secondary school, in order to assess the comprehension of the translated and adapted questionnaire. The data obtained by the pre-tests revealed good psychometric properties such as: Cronbach's alphas (intrinsic motivation: 0.88 ; identified regulation: 0.83 ; introjected regulation: 0.83 ; external regulation: 0.79 ), item-difficulty $[=$ the average score on an item divided by the highest number of points for any one alternative; ideal item-difficulty levels are ranging between 0.20 and 0.80 (see Bühner, 2011); the item-difficulty levels of the German version of the SRQ-A range between 0.36 and 0.83 ] and item-discrimination [ = Pearson product moment correlation between student responses to a particular item and total scores on all other items of the scale; ideal discrimination indices are above 0.30 (see Bühner, 2011); the discrimination indices of the German version of the SRQ-A range between 0.35 and 0.74]. The psychometric properties obtained by the current sample are as follows: Cronbach's alphas (intrinsic motivation: 0.85; identified regulation: 0.86 ; introjected regulation: 0.79 ; external regulation: 0.77 ), item-difficulty (ranging between 0.44 and 0.86 ) and item-discrimination (ranging between 0.33 and $0.74)$.

\section{Teacher questionnaire}

The problems in schools questionnaire by Deci et al. (1981) - German translation by Martinek (2007) - assesses whether teachers tend to be controlling versus autonomy supportive while interacting with their students. The measures are composed of eight vignettes, each of which is followed by four ways of responding to the situation - one is highly controlling, one is moderately controlling, one is moderately autonomy supportive, and one is highly autonomy supportive. Respondents rate the degree of appropriateness of each of the four options (on a seven-point scale) for each of the eight situations. According to the manual, we computed mean scale values for each participant and each subscale. Again we concentrate our analyses on the extreme scales, highly autonomy supportive and highly controlling. Alpha reliabilities for the subscales of the English/German version of the problems in school questionnaire were: highly controlling $=0.73 / 0.75$ and highly autonomy supportive $=0.80 / 0.65$ (for the Englisch original version see Deci et al., 1981, for the German version see Martinek, 2007).

\section{STATISTICAL ANALYSES}

Question 1: Do the executive function tests work?

The executive function tests (dots task and Eriksen flanker task) were analyzed by within-subjects ANOVAs in order to verify, that the student's performances were systematically influenced by the different task conditions. As dependent variables we considered both reaction times and error rate. The independent variable is the task condition (Eriksen flanker task: congruent and incongruent, dots task: congruent, incongruent and mixed). For the dots task the independent variable task condition covers three levels, therefore a significant main effect task condition is further examined by pairwise contrasts.

Question 2: How does teachers' autonomy support relate to children's motivation?

Specific influences on the dependent variables intrinsic motivation and external regulation were analyzed by linear mixed models. Considering that the present study was conducted in a school setting, where students are nested in schools, we used a multilevel modeling approach - the SPSS mixed procedure (SPSS, 2005). The school level was included as random effect to account for common variance. In addition to the random effect "schools," the teacher level had been introduced as random effect, too. But when estimating the mixed model convergence failed. Presumably the variance of this random effect has been too small. Therefore, the present and all following analyses were computed without the random effect teacher level. Random-intercept models were estimated in which the intercepts were allowed to vary randomly but with fixed effects for all predictor variables. The method of estimation applied for all models was restricted maximum likelihood. The two subscales of the problems in schools questionnaire, highly autonomy supportive and highly controlling, were added as fixed effects. To account for possible bias, gender and type of school were included as fixed effects, too.

Question 3: How does children's motivation relate to their executive functions?

Specific influences on the executive functions were analyzed by linear mixed models. Again a multilevel modeling approach, linear mixed models, was used. The school level was included as random effect to account for common variance. The method of estimation was restricted maximum likelihood. The dependent variable executive function was tested by introducing the difference scores of reaction times and error rates following incongruent trials minus congruent ones. These difference scores display the additional allocation of executive function capacities while coping with challenging tasks. The analyses were computed separately for the difference scores of error rate and reaction time and separately for the dots and the Eriksen flanker task. The two subscales of the SRQ, intrinsic motivation and external regulation, were added as fixed effects. To account for possible bias, gender and type of school were included as fixed effects, too.

Question 4: How does teachers' autonomy support relate to their children's executive functions?

In our fourth analyses linear mixed models were used to disclose systematic effects of the teachers' autonomy support on their 
children's executive functions. Again, school level was included as random effect. The dependent variable executive function was tested by introducing the difference scores of reaction times and error rates following incongruent trials minus congruent ones. Analog to the third analysis computations were done separately for the difference scores of error rate and reaction time and separately for the dots and the Eriksen flanker task. The problems in school questionnaire highly autonomy supportive and highly controlling were added as fixed effects. To account for possible bias, gender and type of school were included as fixed effects, too.

\section{RESULTS}

Table 1 shows descriptive statistics for the subscales of the SRQ, the subscales of the problems in school questionnaire and the two executive function tests, the dots and the Eriksen flanker task.

With regard to reaction time and error rate, performance in the dots task was best in the congruent condition, intermediate in the incongruent one, and worst in the mixed condition. Performance in the incongruent and mixed condition can also be viewed as a deviation from performance in the congruent condition (incongruent minus congruent, mixed minus congruent), thus taking into account baseline performance. This deviation was greater for performance in the mixed condition than in the incongruent one.
The mean scores in the Eriksen flanker task reveal very similar: reaction time is faster and error rate is lower in the congruent condition than in the incongruent. The descriptive statistics for the SRQ disclose that children assess themselves to be more often external regulated then to be intrinsic motivated. Intrinsic motivation and external regulation did not correlate (Pearsons $r=0.021$; $p=0.760)$. The participating teachers rate themselves acting much more autonomy supportive than controlling. Highly autonomy supportive and controlling behavior did not correlate (Pearsons $r=-0,115, p=0.162)$.

\section{DO THE EXECUTIVE FUNCTION TESTS WORK?}

Analysing the reaction time of the dots task, the withinsubject ANOVA reveals a significant main effect task condition $\left[F(2,334)=922.171 ; p<0.001 ; \eta_{p}^{2}=0.847\right]$. Contrasts comparing the congruent and the incongruent $[F(1,167)=75.367$; $\left.p<0.001 ; \eta_{p}^{2}=0,311\right]$, as well as the congruent and the mixed condition $\left[F(1,167)=1114.771 ; p<0.001 ; \eta_{p}^{2}=0.870\right]$, show that the congruent trials were followed by the fastest reaction times and the mixed trials were followed by the slowest reaction times with the incongruent trials lying in between. Analysing the error rate of the dots task, the within-subject ANOVA discloses again a significant main effect task condition $[F(2,338)=29.687$; $\left.p<0.001 ; \eta_{p}^{2}=0,149\right]$. Contrasts reveal the following pattern:

Table 1 | Descriptive statistics.

\begin{tabular}{|c|c|c|c|c|}
\hline & Mean & SD & Minimum & Maximum \\
\hline \multicolumn{5}{|l|}{ Dots task } \\
\hline Reaction time: incongruent & 473.54 & 67.66 & 284.20 & 642.99 \\
\hline Reaction time: mixed & 649.67 & 101.04 & 369.42 & 902.41 \\
\hline Error rate: mixed & 0.12 & 0.13 & 0.00 & 0.62 \\
\hline Reaction time: incongruent - congruent & 33.08 & 49.38 & -154.10 & 167.65 \\
\hline Reaction time: mixed - congruent & 209.67 & 82.25 & -77.16 & 419.65 \\
\hline Error rate: incongruent -congruent & 0.04 & 0.19 & -0.59 & 1.00 \\
\hline Reaction time: incongruent & 619.76 & 135.18 & 331.50 & 1526.00 \\
\hline Error rate: congruent & 0.09 & 0.17 & 0.00 & 0.94 \\
\hline Error rate: incongruent & 0.11 & 0.18 & 0.00 & 0.98 \\
\hline Reaction time: incongruent - congruent & 33.78 & 91.83 & -192.91 & 862.67 \\
\hline Error rate: incongruent - congruent & 0.01 & 0.06 & -0.21 & 0.20 \\
\hline \multicolumn{5}{|l|}{ Self-regulation questionnaire } \\
\hline Intrinsic motivation & 1.68 & 0.71 & 0.00 & 3.00 \\
\hline External regulation & 2.05 & 0.55 & 0.56 & 3.00 \\
\hline \multicolumn{5}{|l|}{ Problems in school questionnaire } \\
\hline
\end{tabular}


the error rate following congruent trials is significant lower compared to incongruent $\left[F(1,169)=6.642 ; p=0.011 ; \eta_{p}^{2}=0.038\right]$ and mixed $\left[F(1,169)=97.250 ; p<0.001 ; \eta_{p}^{2}=0.365\right]$ trials. The within-subject ANOVAs of the Eriksen flanker task discloses a significant difference between the incongruent and congruent trials with regard to reaction times [main effect task condition: $F(1,169)=23.002 ; p<0.001 ; \eta_{p}^{2}=0.120$; with faster reaction times following congruent trials] as well as with regard to error rate [main effect task condition: $F(1,169)=7.500$; $p=0.007 ; \eta_{p}^{2}=0.042$; with lower error rates following congruent trials].

These results confirm that the student's responses were systematically stressed by the task conditions. Further analyses consider the difference scores of reaction time and error rate following incongruent trials minus congruent ones. These difference scores take baseline performance into account and display the additional allocation of executive functions while coping with tasks of differing demands (see Davidson etal., 2006).

\section{HOW DOES TEACHERS' AUTONOMY SUPPORT RELATE TO CHILDREN'S MOTIVATION?}

The effects of teacher's behavior on student's motivation styles were examined using linear mixed models.

The results can be seen in Table 2, separately for intrinsic motivation (left part) and external regulation (right part). Children's motivation style is influenced by their teachers' autonomy support. Children, whose teachers rate themselves being highly autonomy supportive, show higher intrinsic motivation ( $B=0.17)$, whereas children, whose teachers assess themselves being highly controlling, disclose higher external regulation styles $(B=0.20)$. Motivation is influenced by gender and school type. Girls reveal higher intrinsic motivation scores compared to boys
( $B=0.24)$ and students of middle schools show lower intrinsic motivation scores $(B=-0.57)$ and higher external regulation scores $(B=0.33)$ compared to primary school children.

Table 2 also provides information about the reduction in variance estimate $\left(R^{2}\right)$ for the within-school portions of the model. All fixed effects together account for about $73 \%$ of the withinschool variability in student's intrinsic motivation and for $88 \%$ of the within-school variability in student's external regulation. Both values of $R^{2}$ are quite high, showing that the data fits well to the regression model. The proportions of variance between schools compared to the total variation (=ICC) add up to $20 \%$ predicting intrinsic motivation and $16 \%$ predicting external regulation. Heck et al. (2010) suggest that the development of a multilevel model is warranted if the ICC is higher than $5 \%$.

\section{HOW DOES CHILDREN'S MOTIVATION RELATE TO THEIR EXECUTIVE FUNCTIONS?}

Table 3 displays the results of the linear mixed model analysis of how children's motivation is related to their executive functions. On the left side of Table 3, the results predicting error rate and reaction time difference scores of the dots task are depicted and on the right side, the results predicting error rate and reaction time difference scores of the Eriksen flanker task are depicted. As can be seen, high intrinsic motivation scores came along with low error rate difference scores (dots task: $B=-0.021$ ) and high external regulation scores are accompanied by high error rate difference scores (dots task: $B=0.036$; Eriksen flanker task: $B=0.040$ ). Thus, intrinsically motivated children reveal better executive functions compared to external regulated children. Reaction times are not affected by the motivational style. The analysis of the dots task also shows, that girls reveal slower reaction times compared to boys $(B=24.23)$ and junior high school students [middle school students $(B=-52.74)$ as well as students from Gymnasien

Table 2 | Results $[B=$ estimates of fixed effects; $\mathrm{SE}(B)=$ standard errors] of linear mixed model analyses predicting children's motivation by teachers' autonomy support.

\begin{tabular}{|c|c|c|c|c|}
\hline \multirow[t]{2}{*}{ Predictors } & \multicolumn{4}{|c|}{ Self-regulation questionnaire } \\
\hline & \multicolumn{2}{|c|}{ Intrinsic motivation } & \multicolumn{2}{|c|}{ External regulation } \\
\hline \multicolumn{5}{|l|}{ Child } \\
\hline Gender (ref.: boys) & $0.24 * *$ & 0.10 & -0.06 & 0.08 \\
\hline Middle schools & $-0.57^{* *}$ & 0.21 & $0.33^{* *}$ & 0.15 \\
\hline Gymnasien & -0.26 & 0.25 & -0.11 & 0.17 \\
\hline \multicolumn{5}{|l|}{ Problems in school questionnaire } \\
\hline Teacher: highly autonomy supportive & $0.17 * *$ & 0.07 & -0.07 & 0.06 \\
\hline Teacher: highly controlling & 0.01 & 0.11 & $0.20 * *$ & 0.08 \\
\hline
\end{tabular}

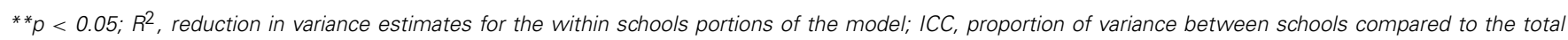
variation; all continuous predictors were grand-mean centered before being included in the model. 
Table 3 | Results [ $B=$ estimates of fixed effects; $S E(B)=$ standard errors] of linear mixed model analyses predicting the executive function difference scores incongruent minus congruent by children's motivation.

\begin{tabular}{|c|c|c|c|c|c|c|c|c|}
\hline \multirow[t]{3}{*}{ Predictors } & \multicolumn{4}{|c|}{ Dots task: incongruent minus congruent } & \multicolumn{4}{|c|}{ Eriksen flanker task: incongruent minus congruent } \\
\hline & \multicolumn{2}{|c|}{ Error rate } & \multicolumn{2}{|c|}{ Reaction time } & \multicolumn{2}{|c|}{ Error rate } & \multicolumn{2}{|c|}{ Reaction time } \\
\hline & $B$ & $\operatorname{SE}(B)$ & $\boldsymbol{B}$ & $\operatorname{SE}(B)$ & $B$ & SE(B) & $\boldsymbol{B}$ & $\operatorname{SE}(B)$ \\
\hline \multicolumn{9}{|l|}{ Child } \\
\hline Gender (ref.: boys) & -0.023 & 0.018 & $24.23^{*}$ & 12.33 & -0.001 & 0.015 & 12.37 & 14.44 \\
\hline \multicolumn{9}{|c|}{ School type (ref.: primary schools) } \\
\hline Middle schools & -0.019 & 0.028 & $-52.74^{* *}$ & 19.40 & -0.002 & 0.029 & -4.09 & 22.71 \\
\hline Gymnasien & -0.038 & 0.031 & $-53.99 * *$ & 20.97 & -0.041 & 0.026 & -19.37 & 24.55 \\
\hline \multicolumn{9}{|c|}{ Self-regulation questionnaire } \\
\hline Intrinsic motivation & $-0.021^{*}$ & 0.013 & -5.21 & 8.89 & -0.001 & 0.011 & -8.87 & 10.40 \\
\hline External regulation & $0.036^{* *}$ & 0.017 & 16.72 & 11.64 & $0.040^{* *}$ & 0.014 & 12.30 & 13.62 \\
\hline$R^{2}$ & 0.51 & & 0.23 & & 0.60 & & 0.19 & \\
\hline ICC & 0.09 & & 0.15 & & 0.06 & & 0.23 & \\
\hline
\end{tabular}

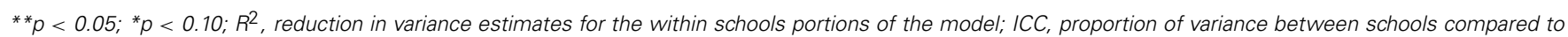
the total variation; all continuous predictors were grand-mean centered before being included in the model.

$(B=-53.99)]$ show faster reaction times compared to primary school children.

Values of $R^{2}$ range from 19 to $60 \%$. The linear mixed models predicting error rate difference scores show a better model fit (51 and 60\%) compared those predicting reaction time difference scores (23 and 19\%).

\section{HOW DOES TEACHERS' AUTONOMY SUPPORT RELATE TO THEIR CHILDREN'S EXECUTIVE FUNCTIONS?}

The results depicting the linear mixed model analysis of the effects of the teacher behavior on their children's executive functions can be seen in Table 4. The left side of Table 4 presents the results concerning error rate and reaction time of the dots task and the right side presents the results concerning error rate and reaction time of the Eriksen flanker task. Children, whose teachers rate themselves being highly autonomy supportive, show better executive functions [defined as lower error rate difference scores performing the dots $(B=-0.037)$ and the Eriksen flanker task $(B=-0.014)]$. Between teachers' highly controlling and their children's motivation style no impact reveals significant. Reaction times are not affected by teachers' autonomy support. Girls reveal lower error rates compared to boys (dots task: $B=-0.098$; Eriksen flanker

Table 4 | Results [ $B=$ estimates of fixed effects; $\mathrm{SE}(B)=$ standard errors] of linear mixed model analyses predicting the executive function difference scores incongruent minus congruent by teachers' autonomy support.

\begin{tabular}{|c|c|c|c|c|c|c|c|c|}
\hline \multirow[t]{2}{*}{ Predictors } & \multicolumn{4}{|c|}{ Dots task: incongruent minus congruent } & \multicolumn{4}{|c|}{ Eriksen flanker task: incongruent minus congruent } \\
\hline & $B$ & $\operatorname{SE}(B)$ & B & $\operatorname{SE}(B)$ & $B$ & $\operatorname{SE}(B)$ & $B$ & $\mathrm{SE}(B)$ \\
\hline \multicolumn{9}{|l|}{ Child } \\
\hline Gender (ref.: boys) & $-0.098^{* *}$ & 0.030 & 12.18 & 7.48 & $-0.014^{*}$ & 0.008 & 13.97 & 14.80 \\
\hline \multicolumn{9}{|l|}{ School type (ref.: primary schools) } \\
\hline Middle schools & -0.032 & 0.059 & $-39.03 * *$ & 14.21 & -0.009 & 0.016 & -4.97 & 25.89 \\
\hline Gymnasien & -0.062 & 0.054 & $-52.00 * *$ & 13.03 & -0.013 & 0.015 & -27.27 & 28.27 \\
\hline \multicolumn{9}{|l|}{ Problems in school questionnaire } \\
\hline Teacher: highly autonomy supportive & $-0.037^{*}$ & 0.022 & -5.85 & 5.33 & $-0.014 * *$ & 0.006 & -3.42 & 10.55 \\
\hline Teacher: highly controlling & 0.018 & 0.027 & 4.19 & 6.82 & 0.002 & 0.008 & 3.62 & 13.37 \\
\hline
\end{tabular}

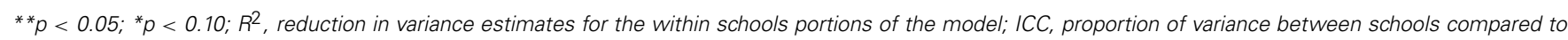
the total variation; all continuous predictors were grand-mean centered before being included in the model. 
task: $B=-0.014)$. For the dots task junior high school students [middle school students $(B=-39.03)$ as well as students from Gymnasien $(B=-52.00)]$ show faster reaction times compared to primary school children.

Values of $R^{2}$ range from 12 to $63 \%$. Again, the linear mixed models predicting error rate difference scores show a better model fit (63 and 59\%) compared those predicting reaction time difference scores (22 and 12\%).

\section{DISCUSSION}

The present study pursues the following objectives: first, the interplay of student's motivation style and their teacher's autonomy support is investigated. Second, systematic impacts of the aforementioned factors on children's executive functions are addressed.

The analysis reveals that teacher's autonomy supportive or controlling behavior is associated with their children's motivation style. High autonomy supportive behavior is positively related to intrinsic motivation whereas high controlling behavior is positively related to external regulation. This result is in accordance with many others studies (Deci et al., 1991; Reeve et al., 2004; Soenens and Vansteenkiste, 2005; Reeve, 2006). Stroet et al. (2013) systematically reviewed 71 empirical studies on the effects of autonomy supportive teaching on student's motivation and engagement for school and found a clear positive association. But, as Stroet et al. (2013) note, most of these studies used student perceptions to measure autonomy supportive teaching. Studies using teacher perceptions are missing. Here the present study can make an important contribution, since we found positive associations of teacher's self-evaluation of their autonomy supportive or controlling behavior and their student's motivation styles.

The present data further discloses that student's motivation styles are related to their executive functions. Students who showed lower error rate difference scores while performing the executive function tasks scored higher in intrinsic motivation and students with higher error rate difference scores more often made use of external regulation strategies. However, the causal relationship between these variables is still unclear. It is possible that external regulation strategies prevent development and training of executive functions. It is likewise possible that student's low executive functions capacities require external regulation strategies. Future research should tackle this.

Doing well in executive function tasks requires that children react to errors when they occur. To minimize future errors they have to learn from them. Past research has shown that autonomy improves self-regulation because it fosters openness to failures (Koestner and Zuckerman, 1994; Hodgins and Liebeskind, 2003; Weinstein et al., 2011). Autonomously acting people "... are less defensive and ego-protective and tend to openly acknowledge negative affect or criticism and personal shortcomings" (cited from Legault and Inzlicht, 2013, p. 125). Keeping in mind that autonomy and motivation are interconnected, we suppose that intrinsic motivation increases attention in performance monitoring during the executive function tasks and improves the reaction to one's errors. External regulation, on the other hand, is associated with decreased attention and error receptivity, resulting in higher error rates. In line with our result, neuroscientists (Fisher et al., 2009; Legault and Inzlicht, 2013) report significant positive correlations of intrinsic motivation with an event related potential, the error-related negativity. This error-related negativity reflects an error detection system that monitors performance and detects incongruity between intended and actual responses (Holroyd and Coles, 2002).

The last analysis focused the impact of teachers' autonomy support on their children's executive functions. Teachers that support autonomy are related to students that produce lower error rate difference scores while performing executive functions tests. Given this significant relationships, from an applied perspective, it is important for teachers to prescind from controlling behavior and to be advised to teach in a more autonomy-supportive fashion. So what can teachers do to enhance their student's motivation and executive functions? Several studies (Reeve et al., 1999; Black and Deci, 2000; Assor et al., 2005) revealed that autonomy supportive environments promote the salience of intrinsic goals (e.g., personal growth) and minimize external incentives (e.g., money) and threats. In order to grasp the importance of an intrinsic goal, students have to freely choose tasks that they perceive as consistent with their goals and interests. Teacher may support this by using phrases such as, "you can," "you might," "if you choose," and "we ask you to," instead of phrases such as "you should," "you have to," "you'd better," and "you must." They further may support autonomy by creating opportunities for students to work in their own way. Teachers should not keep possession of and monopolize the learning material they rather should arrange learning materials so students can "serve themselves." Thus, instead of passively watching and listening students have to organize their own learning process in a self-directed active way. The teacher's task is to offer progress-enabling hints when students seem stuck, to respond to student's questions and comments and to encourage effort and persistence.

In addition to our major results the present analyses further revealed that children's gender and school type are associated with their intrinsic motivation score. It appears that girls display more intrinsic motivation than boys. Usually school-related intrinsic motivation is investigated in a domain-specific way. Most of these studies found that girls achieve higher intrinsic motivation scores for languages and boys for mathematics (e.g., Jacobs et al., 2002; Spinath et al., 2006; Freudenthaler et al., 2008). The present study has questioned intrinsic motivation of boys and girls in a general school-related way. Thus, high scores indicate that girls show stronger willingness to learn and to do well in school (i.e., to achieve good grades and to behave in a more agreeable way). Our result might be a potential mediator of the so-called gender gap in educational achievement (Salisbury et al., 1999), but needs to be assessed in further research. The present study showed that school type is related to intrinsic motivation, whereby older children, who are visiting middle schools and Gymnasien, show a general decrease of intrinsic motivation compared to younger ones, who are visiting primary schools. This result is in line with others (Harter, 1981; Gottfried et al., 2001; Lepper et al., 2005). The decrease in intrinsic motivation is explained by an increasingly controlling school environment. 


\section{LIMITATIONS}

One limitation concerns the study design. We did not have the opportunity to observe the schools by a longitudinal study, all data was raised at a single measurement point. Thus, we are not in a position to make assumptions about potential causal links between the investigated variables. A second limitation is that we did not control for IQ. On average more children with higher IQ are allocated for Gymnasien than middle schools. Since we did not control for IQ we cannot exclude a modulating effect of such a general intelligence variable.

\section{REFERENCES}

Amabile, T. M. (1985). Motivation and creativity: effects of motivational orientation on creative writers. J. Pers. Soc. Psychol. 48, 393-399. doi: 10.1037/00223514.48.2.393

Assor, A., Kaplan, H., Kanat-Maymon, Y., and Roth, G. (2005). Directly controlling teacher behaviors as predictors of poor motivation and engagement in girls and boys: the role of anger and anxiety. Learn. Instruct. 15, 397-413. doi: 10.1016/j.learninstruc.2005.07.008

Assor, A., Kaplan, H., and Roth, G. (2002). Choice is good, but relevance is excellent: autonomy enhancing and suppressing teacher behaviors predicting students' engagement in schoolwork. Br. J. Educ. Psychol. 2, 261-278. doi: $10.1348 / 000709902158883$

Bernier, A., Carlson, S. M., and Whipple, N. (2010). From external regulation to elfregulation: early parenting precursors of young children's executive unctioning. Child Dev. 81, 326-339. doi: 10.1111/j.1467-8624.2009.01397.x

Black, A. E., and Deci, E. L. (2000). The effects of instructors' autonomy support and students' autonomous motivation on learning organic chemistry: a selfdetermination theory perspective. Sci. Educ. 84, 740-756. doi: 10.1002/1098237X(200011)84:6<740::AID-SCE4>3.0.CO;2-3

Blair, C. (2002). School readiness: integrating cognition and emotion in a neurobiological conceptualization of children's functioning at school entry. Am. Psychol. 57, 111-127. doi: 10.1037/0003-066X.57.2.111

Blair, C., and Razza, R. P. (2007). Relating effortful control, executive function, and false belief understanding to emerging math and literacy ability in kindergarten. Child Dev. 78, 647-663. doi: 10.1111/j.1467-8624.2007.01019.x

Brocki, K. C., and Bohlin, G. (2004). Executive functions in children aged 6 to 13: a dimensional and developmental study. Dev. Neuropsychol. 26, 571-593. doi: $10.1207 /$ s15326942dn2602_3

Bühner, M. (2011). Einführung in die Test- und Fragebogenkonstruktion. München: Pearson Studium.

Bull, R., Johnston, R. S., and Roy, J. A. (1999). Exploring the roles of the visualspatial sketch pad and central executive in children's arithmetical skills: views from cognition and developmental neuropsychology. Dev. Neuropsychol. 15, 421-442. doi: 10.1080/87565649909540759

Carlson, S. M. (2005). Developmentally sensitive measures of executive function in preschool children. Dev. Neuropsychol. 28, 595-616. doi: $10.1207 / \mathrm{s} 15326942 \mathrm{dn} 2802 \_3$

Carlson, S. M. (2009). Social origins of executive function development. New Dir. Child Adolesc. Dev. 2009, 87-98. doi: 10.1002/cd.237

Carnegie Council on Adolescent Development. (1995). Great Transitions: Preparing Adolescents for a New Century. New York: Carnegie Corporation.

Carpendale, J., and Lewis, C. (2006). How Children Develop Social Understanding. Malden, MA: Blackwell Publishing.

Casey, B., Giedd, J. N., and Thomas, K. M. (2000). Structural and functional brain development and its relation to cognitive development. Biol. Psychol. 54, 241-257. doi: 10.1016/S0301-0511(00)00058-2

Cepeda, N. J., Kramer, A. F., and Gonzalez de Sather, J. (2001). Changes in executive control across the life span: examination of task-switching performance. Dev. Psychol. 37, 715-730. doi: 10.1037/0012-1649.37.5.715

Chelune, G. J., and Baer, R. A. (1986). Developmental norms for the Wisconsin Card Sorting test. J. Clin. Exp. Neuropsychol. 8, 219-228. doi: 10.1080/01688638608401314

Connell, J. P., and Ryan, R. M. (1986). Manual for the ASRQ: A theory and Assessment of Children's Self-Regulation Within the Academic Domain. Rochester, NY: University of Rochester.
Davidson, M. C., Amso, D., Anderson, L. C., and Diamond, A. (2006). Development of cognitive control and executive functions from 4 to 13 years: evidence from manipulations of memory, inhibition, and task switching. Neuropsychologia 44, 2037-2078. doi: 10.1016/j.neuropsychologia.2006.02.006

Deci, E. L. (1971). Effects of externally mediated rewards on intrinsic motivation. J. Pers. Soc. Psychol. 18, 105. doi: 10.1037/h0030644

Deci, E. L., Koestner, R., and Ryan, R. M. (1999). A meta-analytic review of experiments examining the effects of extrinsic rewards on intrinsic motivation. Psychol. Bull. 125, 627. doi: 10.1037/0033-2909.125.6.627

Deci, E. L., and Ryan, R. M. (1985). Intrinsic Motivation and Self-Determination in Human Behavior. New York: Plenum. doi: 10.1007/978-1-4899-2271-7

Deci, E. L., and Ryan, R. M. (1994). Promoting self-determined education. Scand. J. Educ. Res. 38, 3-14. doi: 10.1080/0031383940380101

Deci, E. L., and Ryan, R. M. (2000). The what and why of goal pursuits: human needs and the self-determination of behavior. Psychol. Inq. 11, 227-268. doi: 10.1207/S15327965PLI1104_01

Deci, E. L., Schwartz, A. J., Sheinman, L., and Ryan, R. M. (1981). An instrument to assess adults' orientations toward control versus autonomy with children: reflections on intrinsic motivation and perceived competence. J. Educ. Psychol. 73, 642-650. doi: 10.1037/0022-0663.73.5.642

Deci, E. L., Vallerand, R. J., Pelletier, L. G., and Ryan, R. M. (1991). Motivation and education: the self-determination perspective. Educ. Psychol. 26, 325-346. doi: 10.1080/00461520.1991.9653137

Diamond, A. (2002). "Normal development of prefrontal cortex from birth to young adulthood: cognitive functions, anatomy, and biochemistry," in Principles of Frontal lobe Function, eds D. T. Stuss and R. T. Knight (New York: Oxford University Press), 466-503.

Diamond, A. (2013). Executive functions. Annu. Rev. Psychol. 64, 135-168. doi: 10.1146/annurev-psych-113011-143750

Diamond, A., Barnett, S., Thomas, J., and Munro, S. (2007a). Preschool program improves cognitive control. Science 318, 1387-1388. doi: 10.1126/science. 1151148

Diamond, A., Barnett, S., Thomas, J., and Munro, S. (2007b). Supporting Online Material for Preschool Program Improves Cognitive Control. Available at: http://www.sciencemag.org/content/318/5855/1387/suppl/DC1 [accessed January 13, 2015].

Duckworth, A. L., and Seligman, M. E. (2005). Self-discipline outdoes IQ in predicting academic performance of adolescents. Psychol. Sci. 16, 939-944. doi: 10.1111/j.1467-9280.2005.01641.x

Eriksen, B. A., and Eriksen, C. W. (1974). Effects of noise letters upon the identification of a target letter in a nonsearch task. Percept. Psychophys. 16, 143-149. doi: 10.3758/BF03203267

Espy, K. A., McDiarmid, M. M., Cwik, M. F., Stalets, M. M., Hamby, A., and Senn, T. E. (2004). The contribution of executive functions to emergent mathematic skills in preschool children. Dev. Neuropsychol. 26, 465-486. doi: 10.1207/s15326942dn2601_6

Fisher, K. R., Marshall, P. J., and Nanayakkara, A. R. (2009). Motivational orientation, error monitoring, and academic performance in middle childhood: a behavioral and electrophysiological investigation. Mind Brain Educ. 3, 56-63. doi: 10.1111/j.1751-228X.2008.01053.X

Fortier, M. S., Vallerand, R. J., and Guay, F. (1995). Academic motivation and school performance: toward a structural model. Contemp. Educ. Psychol. 20, 257-274. doi: 10.1006/ceps.1995.1017

Freudenthaler, H. H., Spinath, B., and Neubauer, A. C. (2008). Predicting school achievement in boys and girls. Eur. J. Personal. 22, 231-245. doi: 10.1002/p er.678

Friedman, N. P., Miyake, A., Young, S. E., DeFries, J. C., Corley, R. P., and Hewitt, J. K. (2008). Individual differences in executive functions are almost entirely genetic in origin. J. Exp. Psychol. Gen. 137, 201-225. doi: 10.1037/0096-3445.13 7.2.201

Fuhs, M. W., and Day, J. D. (2011). Verbal ability and executive functioning development in preschoolers at head start. Dev. Psychol. 47, 404-416. doi: 10.1037/a0021065

Garon, N., Bryson, S. E., and Smith, I. M. (2008). Executive function in preschoolers: a review using an integrative framework. Psychol. Bull. 134, 31. doi: 10.1037/00332909.134.1.31

Gathercole, S. E., Brown, L., and Pickering, S. J. (2003). Working memory assessments at school entry as longitudinal predictors of National Curriculum attainment levels. Educ. Child Psychol. 20, 109-122. 
Gathercole, S. E., and Pickering, S. J. (2000a). Assessment of working memory in six-and seven-year-old children. J. Educ. Psychol. 92, 377. doi: 10.1037/00220663.92.2.377

Gathercole, S. E., and Pickering, S. J. (2000b). Working memory deficits in children with low achievements in the national curriculum at 7 years of age. Br. J. Educ Psychol. 70, 177-194. doi: 10.1348/000709900158047

Gathercole, S. E., Pickering, S. J., Knight, C., and Stegmann, Z. (2004). Working memory skills and educational attainment: evidence from national curriculum assessments at 7 and 14 years of age. Appl. Cogn. Psychol. 18, 1-16. doi: 10.1002/acp.934

Gottfried, A. E., Fleming, J. S., and Gottfried, A. W. (2001). Continuity of academic intrinsic motivation from childhood through late adolescence: a longitudinal study. J. Educ. Psychol. 93, 3-13. doi: 10.1037/0022-0663.93.1.3

Grolnick, W. S. (2013). The Psychology of Parental Control: How Well-Meant Parenting Backfires. New York, NY: Psychology Press.

Grolnick, W. S., Ryan, R. M., and Deci, E. L. (1991). The inner resources for schoo performance: motivational mediators of children's perceptions of their parents. J. Educ. Psychol. 83, 508-517. doi: 10.1037/0022-0663.83.4.508

Guay, F., Ratelle, C. F., and Chanel, J. (2008). Optimal learning in optimal contexts: the role of self-determination in education. Can. Psychol. 49, 233-240. doi: $10.1037 / \mathrm{a} 0012758$

Guay, F., and Vallerand, R. J. (1997). Social context, students' motivation, and academic achievement: toward a process model. Soc. Psychol. Educ. 1, 211-233. doi: 10.1007/BF02339891

Hammond, S. I., Müller, U., Carpendale, J. I., Bibok, M. B., and LiebermannFinestone, D. P. (2012). The effects of parental scaffolding on preschoolers executive function. Dev. Psychol. 48, 271-281. doi: 10.1037/a0025519

Harter, S. (1981). A new self-report scale of intrinsic versus extrinsic orientation in the classroom: motivational and informational components. Dev. Psychol. 17, 300-312. doi: 10.1037/0012-1649.17.3.300

Heck, R. H., Thomas, S. L., and Tabata, L. N. (2010). Multilevel and Longitudinal Modeling with IBM SPSS. New York: Taylor \& Francis.

Hodgins, H. S., and Liebeskind, E. (2003). Apology versus defense: antecedents and consequences. J. Exp. Soc. Psychol. 39, 297-316. doi: 10.1016/S0022 1031(03)00024-6

Holroyd, C. B., and Coles, M. G. (2002). The neural basis of human error processing: reinforcement learning, dopamine, and the error-related negativity. Psychol. Rev. 109, 679-709. doi: 10.1037/0033-295X.109.4.679

Hughes, C. H., and Ensor, R. A. (2009). How do families help or hinder the emergence of early executive function? New Dir. Child Adolesc. Dev. 2009, 35-50. doi: $10.1002 / \mathrm{cd} .234$

Huizinga, M., Dolan, C. V., and van der Molen, M. W. (2006). Age-related change in executive function: developmental trends and a latent variable analysis. Neuropsychologia, 44, 2017-2036. doi: 10.1016/j.neuropsychologia.2006.01.010

Jacobs, J. E., Lanza, S., Osgood, D. W., Eccles, J. S., and Wigfield, A. (2002). Changes in children's self-competence and values: gender and domain differences across grades one through twelve. Child Dev. 73, 509-527. doi: 10.1111/1467-862 4.00421

Jarvis, H. L., and Gathercole, S. E. (2003). Verbal and non-verbal working memory and achievements on national curriculum tests at 11 and 14 years of age. Educ. Child Psychol. 20, 123-140.

Kail, R. V. (2003). "Information processing and memory”, in Well-Being: Positive Development Across the life Course eds M. H. Bornstein, L. Davidson, C. L. M. Keyes, and K. A. Moore (Mahwah, NJ: Lawrence Erlbaum), 269-280.

Koestner, R., and Zuckerman, M. (1994). Causality orientations, failure, and achievement. J. Pers. 62, 321-346. doi: 10.1111/j.1467-6494.1994.tb00300.x

Landry, S. H., Miller-Loncar, C. L., Smith, K. E., and Swank, P. R. (2002). The role of early parenting in children's development of executive processes. Dev. Neuropsychol. 21, 15-41. doi: 10.1207/S15326942DN2101_2

Legault, L., and Inzlicht, M. (2013). Self-determination, self-regulation, and the brain: autonomy improves performance by enhancing neuroaffective responsiveness to self-regulation failure. J. Pers. Soc. Psychol. 105, 123-138. doi: $10.1037 / \mathrm{a} 0030426$

Lehto, J. (1995). Working memory and school achievement in the ninth form. Educ. Psychol. 15, 271-281. doi: 10.1080/0144341950150304

Lepper, M. R., Corpus, J. H., and Iyengar, S. S. (2005). Intrinsic and extrinsic motivational orientations in the classroom: age differences and academic correlates. J. Educ. Psychol. 97, 184-196. doi: 10.1037/0022-0663.97.2.184
Lewis, C., and Carpendale, J. I. (2009). Introduction: links between social interaction and executive function. New Dir. Child Adolesc. Dev. 2009, 1-15. doi: $10.1002 / \mathrm{cd} .232$

Lorsbach, T. C., Wilson, S., and Reimer, J. F. (1996). Memory for relevant and irrelevant information: evidence for deficient inhibitory processes in language/learning disabled children. Contemp. Educ. Psychol. 21, 447-466. doi: 10.1006/ceps.1996.0030

Lu, C.-H., and Proctor, R. W. (1995). The influence of irrelevant location information on performance: a review of the Simon and spatial Stroop effects. Psychon. Bull. Rev. 2, 174-207. doi: 10.3758/BF03210959

Martinek, D. (2007). Die Ungewissheit im Lehrberuf: Orientierungsstil, Motivationsstrategie und Bezugsnorm-Orientierung bei Lehrer/innen. Hamburg: Verlag Dr. Kovač.

McClelland, M. M., Cameron, C. E., Connor, C. M., Farris, C. L., Jewkes, A. M., and Morrison, F. J. (2007). Links between behavioral regulation and preschoolers' literacy, vocabulary, and math skills. Dev. Psychol. 43, 947-959. doi: 10.1037/00121649.43.4.947

McLean, J. F., and Hitch, G. J. (1999). Working memory impairments in children with specific arithmetic learning difficulties. J. Exp. Child Psychol. 74, 240-260. doi: 10.1006/jecp.1999.2516

Miyake, A., Friedman, N. P., Emerson, M. J., Witzki, A. H., Howerter, A., and Wager, T. D. (2000). The unity and diversity of executive functions and their contributions to complex "frontal lobe" tasks: a latent variable analysis. Cogn. Psychol. 41, 49-100. doi: 10.1006/cogp.1999.0734

Mizuno, K., Tanaka, M., Fukuda, S., Imai-Matsumura, K., and Watanabe, Y. (2011). Relationship between cognitive function and prevalence of decrease in intrinsic academic motivation in adolescents. Behav. Brain Funct. 7, 4. doi: 10.1186/17449081-7-4

Ozonoff, S., and Jensen, J. (1999). Brief report: specific executive function profiles in three neurodevelopmental disorders. J. Autism. Dev. Disord. 29, 171-177. doi: 10.1023/A:1023052913110

Patrick, H., Anderman, L. H., and Ryan, A. M. (2012). "Social motivation and the classroom social environment," in Goals, Goal Structures, and Patterns of Adaptive Learning ed. C. Midgley (New York: Routledge), 85-108.

Pennington, B. F., and Ozonoff, S. (1996). Executive functions and developmental psychopathology. J. Child Psychol. Psychiatry 37, 51-87. doi: 10.1111/j.14697610.1996.tb01380.x

PISA-Konsortium Deutschland. (2008). PISA 2006 in Deutschland. Die Kompetenzen der Jugendlichen im dritten Ländervergleich. Münster: Waxmann.

Reeve, J. (2006). Teachers as facilitators: what autonomy-supportive teachers do and why their students benefit. Elem. Sch. J. 106, 225-236. doi: 10.1086/501484

Reeve, J. (2009). Why teachers adopt a controlling motivating style toward students and how they can become more autonomy supportive. Educ. Psychol. 44, 159-175. doi: 10.1080/00461520903028990

Reeve, J., Bolt, E., and Cai, Y. (1999). Autonomy-supportive teachers: how they teach and motivate students. J. Educ. Psychol. 91, 537. doi: 10.1037/0022-0663.9 1.3 .537

Reeve, J., and Jang, H. (2006). What teachers say and do to support students' autonomy during a learning activity. J. Educ. Psychol. 98, 209-218. doi: 10.1037/0022-0663.98.1.209

Reeve, J., Jang, H., Carrell, D., Jeon, S., and Barch, J. (2004). Enhancing students' engagement by increasing teachers' autonomy support. Motiv. Emot. 28, 147-169. doi: 10.1023/B:MOEM.0000032312.95499.6f

Reeve, J., Jang, H., Hardre, P., and Omura, M. (2002). Providing a rationale in an autonomy supportive way as a strategy to motivate others during an uninteresting activity. Motiv. Emot. 26, 183-207. doi: 10.1023/A:1021711629417

Russell, J., Jarrold, C., and Henry, L. (1996). Working memory in children with autism and with moderate learning difficulties. J. Child Psychol. Psychiatry 37, 673-686. doi: 10.1111/j.1469-7610.1996.tb01459.x

Ryan, R. M., and Connell, J. P. (1989). Perceived locus of causality and internalization: examining reasons for acting in two domains. J. Pers. Soc. Psychol. 57, 749-761. doi: 10.1037/0022-3514.57.5.749

Ryan, R. M., and Deci, E. L. (2000). Self-determination theory and the facilitation of intrinsic motivation, social development, and well-being. Am. Psychol. 55, 68-78. doi: 10.1037/0003-066X.55.1.68

Ryan, R. M., Stiller, J. D., and Lynch, J. H. (1994). Representations of relationships to teachers, parents, and friends as predictors of academic motivation and selfesteem. J. Early Adolesc. 14, 226-249. doi: 10.1177/027243169401400207 
Salisbury, J., Rees, G., and Gorard, S. (1999). Accounting for the differential attainment of boys and girls at school. Sch. Leadersh. Manag. 19, 403-426. doi: $10.1080 / 13632439968943$

Sesma, H. W., Mahone, E. M., Levine, T., Eason, S. H., and Cutting, L. E. (2009). The contribution of executive skills to reading comprehension. Child Neuropsychol. 15, 232-246. doi: 10.1080/09297040802220029

Soenens, B., and Vansteenkiste, M. (2005). Antecedents and outcomes of self-determination in 3 life domains: the role of parents' and teachers' autonomy support. J. Youth Adolesc. 34, 589-604. doi: 10.1007/s10964-0058948-y

Spinath, B., Spinath, F. M., Harlaar, N., and Plomin, R. (2006). Predicting school achievement from general cognitive ability, self-perceived ability, and intrinsic value. Intelligence 34, 363-374. doi: 10.1016/j.intell.2005.11.004

SPSS. (2005). Linear Mixed Effects Modeling in SPSS: An Introduction to the MIXED Procedure. Technical Report LMEMWP-0305. Chicago, IL: SPSS. Available from: http://www.spss.ch/upload/1126184451_Linear\%20Mixed\%20Effects\%20 Modeling\%20in\%20SPSS.pdf

St Clair-Thompson, H. L., and Gathercole, S. E. (2006). Executive functions and achievements in school: shifting, updating, inhibition, and working memory. Q. J. Exp. Psychol. 59, 745-759. doi: 10.1080/17470210500162854

Stroet, K., Opdenakker, M.-C., and Minnaert, A. (2013). Effects of need supportive teaching on early adolescents' motivation and engagement: a review of the literature. Educ. Res. Rev. 9, 65-87. doi: 10.1016/j.edurev.2012.11.003

Swanson, H. L. (1993). Working memory in learning disability subgroups. J. Exp. Child Psychol. 56, 87-114. doi: 10.1006/jecp.1993.1027

Swanson, H. L., Ashbaker, M. H., and Lee, C. (1996). Learning-disabled readers' working memory as a function of processing demands. J. Exp. Child Psychol. 61, 242-275. doi: 10.1006/jecp.1996.0016

Swanson, H. L., and Berninger, V. W. (1994). "Working memory as a source of individual differences in children's writing," in Children's Writing: Toward a Process Theory of Development of Skilled Writing, ed. E. C. Butterfield (London: Greenwich), 31-56.

Swanson, H. L., and Berninger, V. (1995). The role of working memory in skilled and less skilled readers' comprehension. Intelligence 21, 83-108. doi: 10.1016/0160 2896(95)90040-3

Swanson, H. L., Sáez, L., Gerber, M., and Leafstedt, J. (2004). Literacy and cognitive functioning in bilingual and nonbilingual children at or not at risk for reading disabilities. J. Educ. Psychol. 96, 3-18. doi: 10.1037/0022-0663.96.1.3

Torsheim, T., and Wold, B. (2001). School-related stress, support, and subjective health complaints among early adolescents: a multilevel approach. J. Adolesc. 24, 701-713. doi: 10.1006/jado.2001.0440

Tsai, Y. M., Kunter, M., Lüdtke, O., Trautwein, U., and Ryan, R. M. (2008). What makes lessons interesting? The role of situational and individual factors in three school subjects. J. Educ. Psychol. 100, 460-472. doi: 10.1037/0022-0663.10 0.2 .460

Vallerand, R. J. (1997). "Toward a hierarchical model of intrinsic and extrinsic motivation," in Advances in Experimental Social Psychology, Vol. 29, ed. M. P. Zanna (San Diego, CA: Academic Press), 271-360.
Vallerand, R. J., Fortier, M. S., and Guay, F. (1997). Self-determination and persistence in a real-life setting: toward a motivational model of high school dropout. J. Pers. Soc. Psychol. 72, 1161-1176. doi: 10.1037/0022-3514.72.5.1161

van der Molen, M. W. (2000). Developmental changes in inhibitory processing: evidence from psychophysiological measures. Biol. Psychol. 54, 207-239. doi: 10.1016/S0301-0511(00)00057-0

van der Sluis, S., de Jong, P. F., and van der Leij, A. (2007). Executive functioning in children, and its relations with reasoning, reading, and arithmetic. Intelligence 35, 427-449. doi: 10.1016/j.intell.2006.09.001

Vansteenkiste, M., Simons, J., Lens, W., Sheldon, K. M., and Deci, E. L. (2004). Motivating learning, performance, and persistence: the synergistic effects of intrinsic goal contents and autonomy-supportive contexts. J. Pers. Soc. Psychol. 87, 246-260. doi: 10.1037/0022-3514.87.2.246

Vuontela, V., Steenari, M.-R., Carlson, S., Koivisto, J., Fjällberg, M., and Aronen, E. T. (2003). Audiospatial and visuospatial working memory in 6-13 year old school children. Learn. Memory 10, 74-81. doi: 10.1101/lm.53503

Weinstein, N., Deci, E. L., and Ryan, R. M. (2011). Motivational determinants of integrating positive and negative past identities. J. Pers. Soc. Psychol. 100, 527-544. doi: $10.1037 / \mathrm{a} 0022150$

Welsh, M. C., Pennington, B. F., and Groisser, D. B. (1991). A normativedevelopmental study of executive function: a window on prefrontal function in children. Dev. Neuropsychol. 7, 131-149. doi: 10.1080/87565649109540483

Wentzel, K. R. (2002). Are effective teachers like good parents? Teaching styles and student adjustment in early adolescence. Child Dev. 73, 287-301. doi: 10.1111/1467-8624.00406

Wood, D., Bruner, J. S., and Ross, G. (1976). The role of tutoring in problem solving. J. Child Psychol. Psychiatry 17, 89-100. doi: 10.1111/j.1469-7610.1976.tb00381.x Yamauchi, H., Kumagai, Y., and Kawasaki, Y. (1999). Perceived control, autonomy, and self-regulated learning strategies among Japanese high school students. Psychol. Rep. 85, 779-798. doi: 10.2466/pr0.1999.85.3.779

Conflict of Interest Statement: The authors declare that the research was conducted in the absence of any commercial or financial relationships that could be construed as a potential conflict of interest.

Received: 14 October 2014; accepted: 28 January 2015; published online: 13 February 2015.

Citation: Sosic-Vasic Z, Keis O, Lau M, Spitzer M and Streb J (2015) The impact of motivation and teachers' autonomy support on children's executive functions. Front. Psychol. 6:146. doi: 10.3389/fpsyg.2015.00146

This article was submitted to Developmental Psychology, a section of the journal Frontiers in Psychology.

Copyright (C) 2015 Sosic-Vasic, Keis, Lau, Spitzer and Streb. This is an open-access article distributed under the terms of the Creative Commons Attribution License (CC BY). The use, distribution or reproduction in other forums is permitted, provided the original author(s) or licensor are credited and that the original publication in this journal is cited, in accordance with accepted academic practice. No use, distribution or reproduction is permitted which does not comply with these terms. 